Date of Issue: April 13, 1981

Distribution Category: UC-38

\title{
RESIDUAL CONTAMINANTS IN DYE-PENETRANT TESTING
}

\author{
J. F. McLaughlin \\ P. G. Schneider \\ Instrumentation and Characterization Department \\ Y-12 Development Division \\ M. H. Eager \\ Y-12 Plant Laboratory \\ Product Certification Division

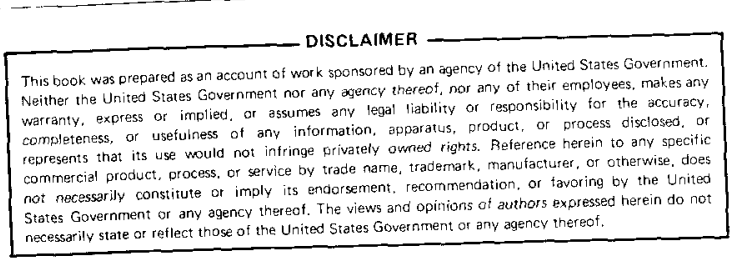

This document is

PUBLICLY RELEASABLE

Authorizing Official

Date: $\quad 8 \cdot 6 \cdot 06$

Oak Ridge $Y-12$ Plant

P. O. Box Y, Oak Ridge, Tennessee 37830

Prepared for the Department of Energy

Under US Government Contract W-7405-eng-26 


\section{DISCLAIMER}

This report was prepared as an account of work sponsored by an agency of the United States Government. Neither the United States Government nor any agency Thereof, nor any of their employees, makes any warranty, express or implied, or assumes any legal liability or responsibility for the accuracy, completeness, or usefulness of any information, apparatus, product, or process disclosed, or represents that its use would not infringe privately owned rights. Reference herein to any specific commercial product, process, or service by trade name, trademark, manufacturer, or otherwise does not necessarily constitute or imply its endorsement, recommendation, or favoring by the United States Government or any agency thereof. The views and opinions of authors expressed herein do not necessarily state or reflect those of the United States Government or any agency thereof. 


\section{DISCLAIMER}

Portions of this document may be illegible in electronic image products. Images are produced from the best available original document. 


\section{ABSTRACT}

Components of the dye-penetrant-testing process were characterized by microanalytical methods. Particulate material of a size range, which was small enough to plug the small leaks in thin-walled cans, was found. Testing of simulated leaks before and after dye-penetrant examination showed that the dye-penetrant testing had a high probability of plugging leaks $<1 \times 10^{-4} \mathrm{~atm}-\mathrm{cm}^{3} / \mathrm{s}$ of helium in size. 


\section{CONTENTS}

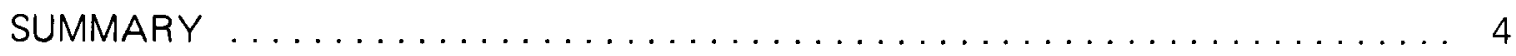

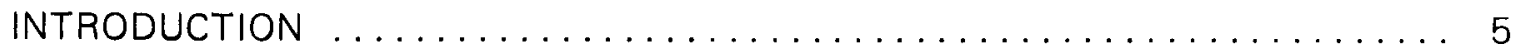

RESIDUAL CONTAMINANTS IN DYE-PENETRANT TESTING $\ldots \ldots \ldots \ldots \ldots$

Experimental Work . . . . . . . . . . . . . . . . . . . . . . 6

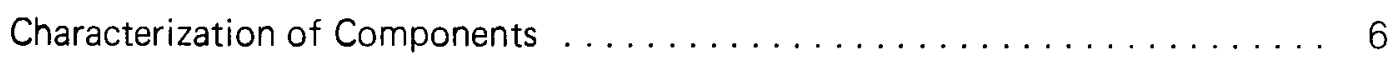

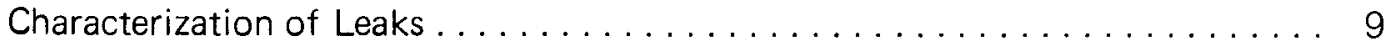

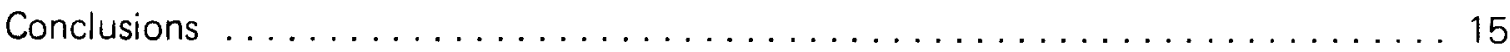

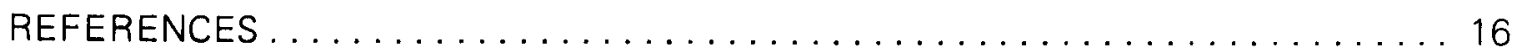




\section{SUMMARY}

The component materials of the dye-penetrant process were characterized using optical and transmission electron microscopy (TEM). All of the components except the developers were particle-free. Particulates found in the developers, a mixture of titanium dioxide $\left(\mathrm{TiO}_{2}\right)$ and calcium carbonate $\left(\mathrm{CaCO}_{3}\right)$, were found to have a biomodal size distribution with size ranges of 0.3 to $1.5 \mu \mathrm{m}$ for the large particles and 0.02 to $0.06 \mu \mathrm{m}$ for the small particles.

Testing of simulated leaks, after subjecting them to components of the dye-penetrant procedure and to the dye-penetrant test itself, showed that leaks of $<1 \times 10^{-4} \mathrm{~atm}-\mathrm{cm}^{3} / \mathrm{s}$ helium are susceptible to plugging. Examination of dye-penetrant-tested leaks after the cleaning procedure at the end of the test showed retention in the leaks of the particulates from the developers used in the test. Results of this study indicate there is a high probability that leaks $<1 \times 10^{-4} \mathrm{~atm}-\mathrm{cm}^{3} / \mathrm{s}$ will be plugged or significantly altered in leak rate; and, consequently, the reliability of the helium leak certification is significantly reduced. 


\section{INTRODUCTION}

Thin-walled cans have the potential for cracking and, consequently, leaking as a result of a welding operation that attaches an outgassing tube to the can. In order to provide a means of quality control, the cans are subjected to a dye-penetrant test to check all welds for cracks.

A problem with the dye-penetrant procedure has been that through-wall cracks detected by the dye-penetrant procedure often are not detected as leaks when checked with a helium leak detector. Previous studies of surfaces subjected to dye-penetrant testing ${ }^{1}$ have shown that the surfaces were, in some cases, actually cleaned by the components of the dye penetrant. However, these studies addressed only the metal surfaces and did not deal with through-wall cracks.

It is clear that a choice between detecting leaks and cracks must be made. A helium leak check cannot detect cracks unless they are through-wall cracks. If a test for surface cracks (potential future leaks) is desired, dye-penetrant testing is the only economically feasible method; but dye testing has a history of plugging existing leaks. This study was undertaken to determine the potential of the dye-penetrant-testing procedures for altering leak rates measured by helium-leak-rate certification techniques.

Presently, two different dye-penetrant testing procedures are in use in the Oak Ridge Y-12 Plant. (a) One procedure involves the following steps: (1) clean the part to be inspected with Magnaflux Spotcheck SKC-S cleaner; (b) (2) allow sufficient time for the evaporation of the cleaner from the part; (3) apply Magnaflux ZL-30A penetrant to the part by dipping or brushing; (4) allow the penetrant to remain on the part for approximately $10 \mathrm{~min}$; (5) dip the part into Magnaflux ZE-3 emulsifier; (6) allow the emulsifier to remain on the part for approximately $2-1 / 2 \mathrm{~min}$; (7) wash the part with water until the part looks clean when examined under ultraviolet (black) light; (8) dry the part in an oven at $57^{\circ} \mathrm{C}\left(135^{\circ} \mathrm{F}\right)$ for $30 \mathrm{~min}$; (9) apply Zyglo (b) ZP-9 developer to the part by spraying; (10) wait $3 \mathrm{~min}$ and inspect the part under ultraviolet light. After the inspection, the part is cleaned with demineralized water to remove the developer and then dried, using lint-free paper wipes.

Another dye-penetrant procedure uses a color-contrast penetrant (red dye) to perform the test. This procedure is as follows: (1) spray or brush a layer of Magnaflux SKD-S developer onto a weld; (2) apply Magnaflux SKL-S penetrant to the other side of the weld with a soft cloth or brush; (3) allow the penetrant and the developer to remain on the weld for $20 \mathrm{~min}$ before inspecting for penetrant indications. After inspection, the surface is cleaned by wiping the developer off with a clean, soft cloth. The penetrant is removed by alternately washing with Magnaflux Spotcheck SKC-S cleaner and blowing dry with instrument air.

(a) Operated by the Union Carbide Corporation, Nuclear Division, for the Department of Energy.

(b) Spotcheck and Zyglo are registered trademarks of the Magnaflux Corporation, Chicago. 


\section{RESIDUAL CONTAMINANTS IN DYE-PENETRANT TESTING}

\section{EXPERIMENTAL WORK}

\section{Characterization of Components}

Each of the components of the dye-penetrant processes was examined for the presence of particulate materials using optical and TEM. The results of these examinations are summarized in Table 1. Since the two developers are the only components of the dye-penetrant process that contain particulates, each of the developers was sprayed onto a glass plate; and the particles were dispersed for microscopy. Figures 1 and 2 show transmission electron micrographs of typical fields of the particulates found in Zyglo ZP-9 developer. As can be seen from Figure 1, there are two distinct size ranges of the particulates. Figure 2 shows the morphology of the smaller particles. Particle size distributions were determined for each of the

Table 1

PARTICULATE CONTENT OF DYE-PENETRANT COMPONENTS

\begin{tabular}{llc}
\hline \multicolumn{1}{c}{ Component } & \multicolumn{1}{c}{$\begin{array}{c}\text { Optical } \\
\text { Microscopy }\end{array}$} & $\begin{array}{c}\text { Transmission } \\
\text { Electron } \\
\text { Microscopy }\end{array}$ \\
\hline $\begin{array}{l}\text { Spotcheck SKC-S Cleaner/Remover } \\
\text { Penetrant ZL-30A } \\
\text { (Green Dye) }\end{array}$ & No & No \\
$\begin{array}{l}\text { Emulsifier ZE-3 } \\
\text { Developer ZP-9 }\end{array}$ & No & No \\
Developer SKD-S & No & No \\
Color-Contrast Penetrant SKL-S & Yes & Yes \\
\hline
\end{tabular}
two size ranges present. Figure 3 shows the size distribution curves for the larger particles. One-half of the particles are $0.32 \mu \mathrm{m}$ in diameter or less. The size distribution curves for the smaller particles are shown in Figure 4. One-half of the smaller particles are $0.03 \mu \mathrm{m}$ in diameter or less. X-ray diffraction examination showed the particles to be a mixture of $\mathrm{TiO}_{2}$ and $\mathrm{CaCO}_{3}$.

The results of the examination of Spotcheck SKD-S developer are shown in Figures 5 through 8 . Figures 5 and 6 are typical transmission electron micrographs of the particulate material found in Spotcheck SKD-S developer. Just as in the case of the Zyglo ZP-9, this developer contains a bimodal distribution of particles. Figure 7 is a particle-size-distribution curve for the large particles in this sample. One-half of the particles were found to be $0.44 \mu \mathrm{m}$ or less in diameter. The particle-size-distribution curves for the small particles are shown in Figure 8. One-half of the small particles are $0.03 \mu \mathrm{m}$ or less in diameter. The X-ray diffraction examination showed the particles to be a mixture of $\mathrm{TiO}_{2}$ and $\mathrm{CaCO}_{3}$.

The examination of the dye-penetrant components shows that both developers contain particulate material. The size range of the particulate material found in both developers is such that the particulates could easily become lodged in small cracks and leaks in thin-walled vessels. The calculated hole sizes for $10^{-6}$ atm- $\mathrm{cm}^{3} / \mathrm{s}$ helium leaks vary in diameter from 0.7 to $0.9 \mu \mathrm{m}$ for sheets of metal from 0.127 to $0.254 \mathrm{~mm}$ in thickness, respectively. 2 

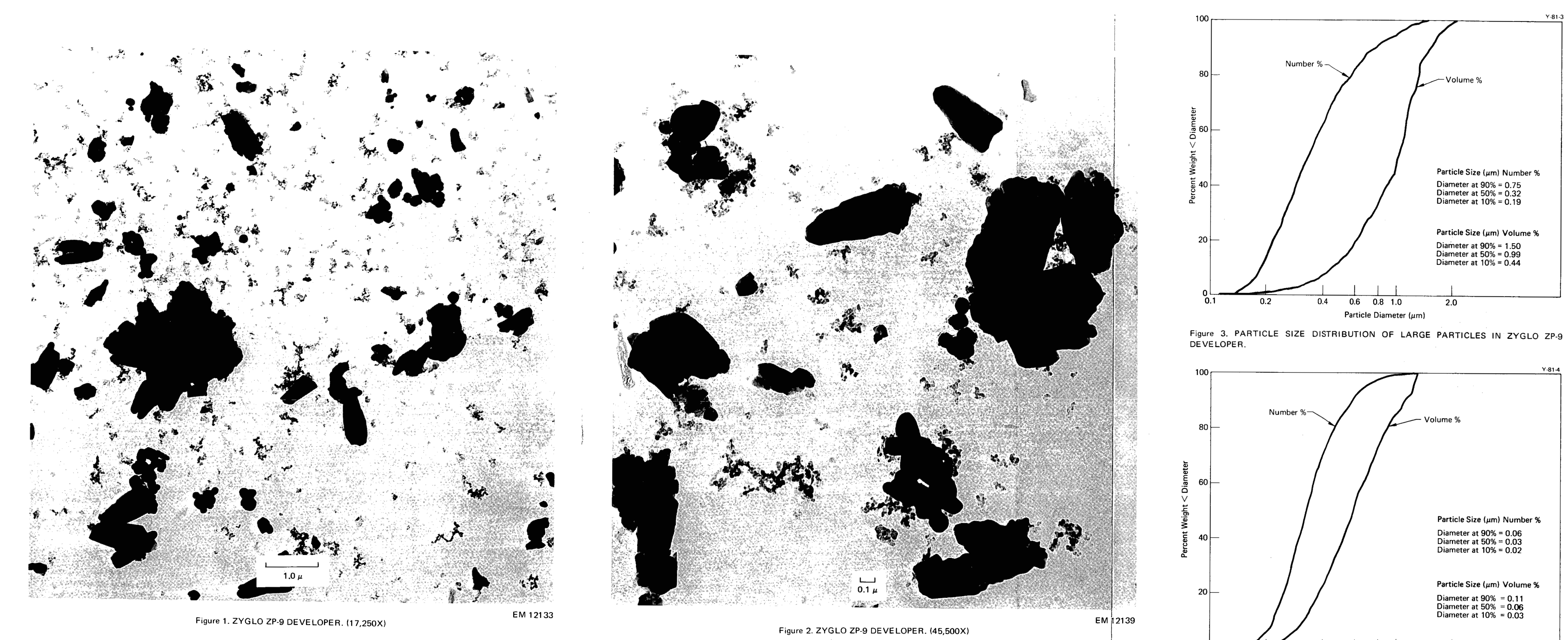

Figure 3. PARTICLE SIZE DISTRiBUTION OF LARGE PARTICLES IN ZYGLO ZP.9
DEVELLPER.

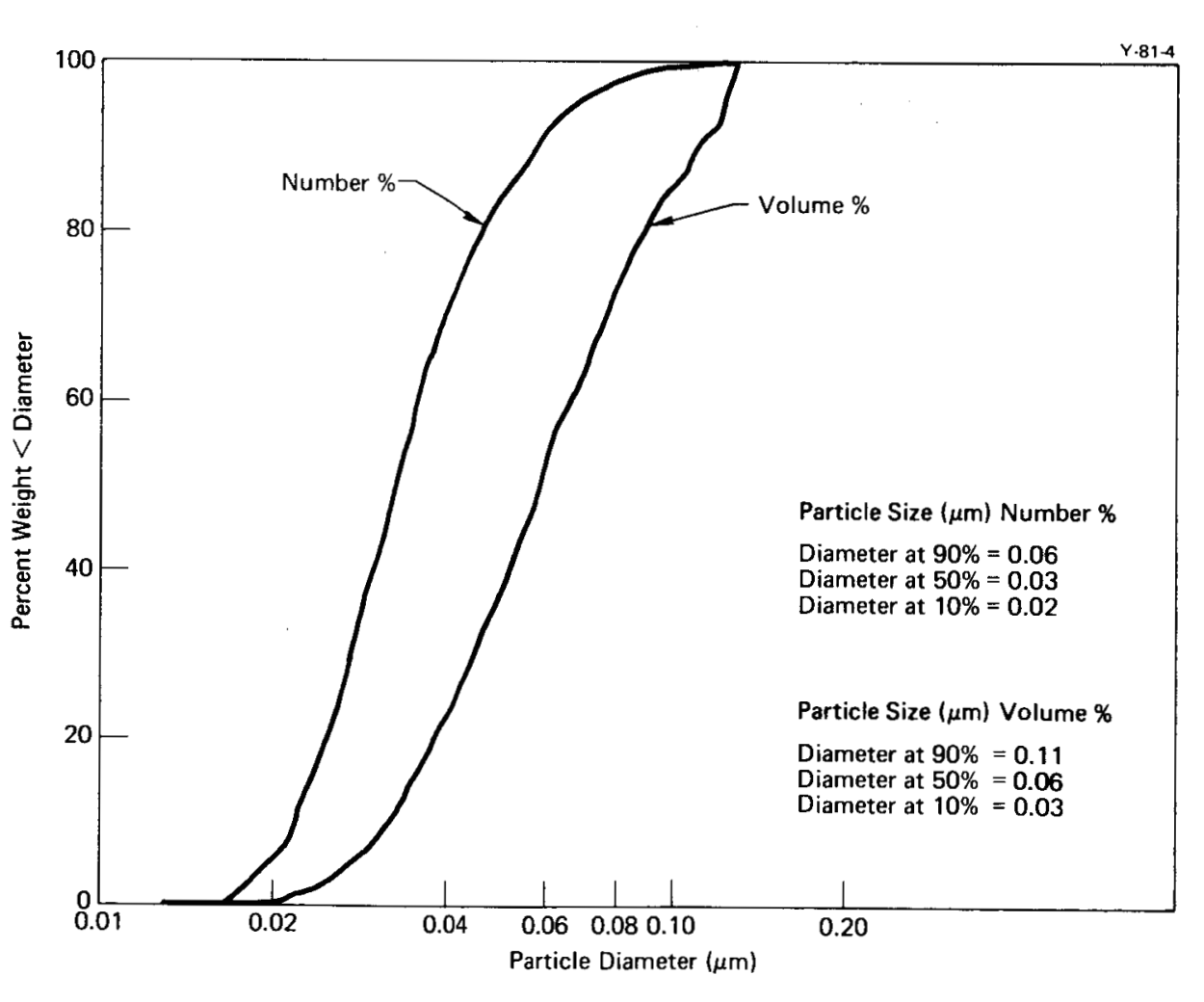



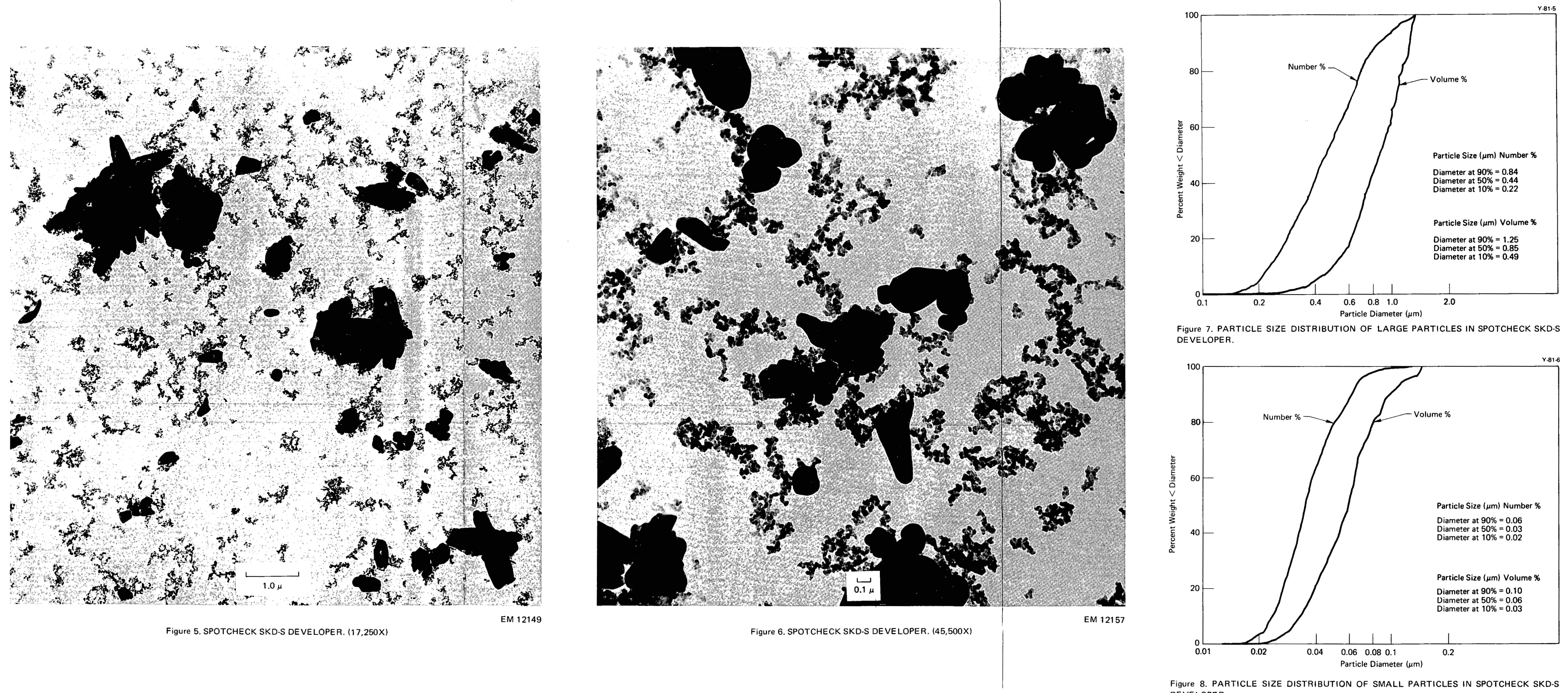
Characterization of Leaks

Since the microanalytical examination of the dye-penetrant components showed that the developers contained particulates that could plug leaks during a dye-penetrant evaluation, a for testing. During, a series of crimped stanless steel tubing artificial leaks were prepared for testing. During the (n) ZL-30A penetrant (green dye), the ZE-3 emulsifier, and the SKL-S color contrast penetrant all had low vapor pressures at room temperature. Thus, it appears that if the emulsifier or the dye can get into a leak, it alone can effectively plug the crack (so that it appears to be leak tight) for some finite period of time or reduce the leak rate below detectable levels $\left(<1 \times 10^{-7}\right.$ atm- $\mathrm{cm} 3 / \mathrm{s}$ helium for the $Y-12$ Assembly Division's present capabilities). A simple experiment was performed to demonstrate the effect of the ZE-3 emulsifier on leak rates. Two crimped stainless steel tubes with measured leak rates of $4 \times 10^{-6} \mathrm{~atm}-\mathrm{cm}^{3} / \mathrm{s}$ holium Two $5 \times 10^{-4}$ atm $\mathrm{cm}^{3} / \mathrm{s}$ heliur and $5 \times 10^{-4}$ am $\mathrm{cm}^{3} / \mathrm{s}$ helum, respectively, were dipped in $Z E 3$ emulsifier, wiped clean, and rechecked for leak rate. Both leaks were clogged to $<1$ which dramatically demonstrated the deleterious effect of the emulsifier on the leak-rate measurement.

A second experiment was performed on seven stainless steel crimped tubes. One of these leaks (Leak A) which had a measured leak rate of $5 \times 10^{-5}$ atm- $\mathrm{cm}^{3} / \mathrm{s}$ helium was examined in the optical microscope and is shown in the micrograph in Figure 9. The crimped orifice of the leak is the oblate area at the center of the micrograph indicated by the arrow. This leak, along with six others for which the leak rates had been determined, was subjected to the along with six others for which the leak rates had been determined, was subjected to the
standard dye-penetrant test procedure using Spotcheck SKL-S color-contrast penetrant (red dye). Each of the leaks was then checked with a helium leak detector and the results are presented in Table 2. All of the tubes gave a dye indication visible to the eye, except $F$ (which was barely detectable). These data indicate that leaks $>1 \times 10^{-4} \mathrm{~atm}-\mathrm{cm} 3 / \mathrm{s} \mathrm{helium}$ are unaffected by the dye-penetrant procedure. Of the five leaks, $₹ 1 \times 10^{-4}$ atm- $\mathrm{cm}^{3} / \mathrm{s}$ helium, one was plugged, three were partially plugged, and one was unaffected. The leak retes of these seven leaks were rechecked after 1 week, and the results included in Table 2 rates of these seven leaks were rechecked after 1 week, and the ralts included in Table 2 . These data indicat that three of the leaks were unaffected (Tubes B, D, and G), three of the eaks were low was greater. This indicates the unpredictability of leak plugging by dye-testing materials.

Tubes A, B, C, D, and E were examined by optical microscopy following the dye-penetrant and helium-leak-check tests. Figure 10 is a black-and-white micrograph of Leak $A$ (compare with Figure 9) after the dye-penetrant test. Since the black-and-white micrograph makes it impossible to observe and appreciate the retention of the visible red dye Figure 11 is (t) each of these leaks had been subjected to the standard cleaning procedure at the end of the color contrast dye-penetrant test described previously. The grayish, indistinct patches seen in Figure 11 suggest possible retention of particles from the developer. Figures 12 through 15 are black-and-white micrographs of Leaks E, D, B, and C, respectively. In each case, the leaks showed retained red dye and possibly retained particulates from the developer. 


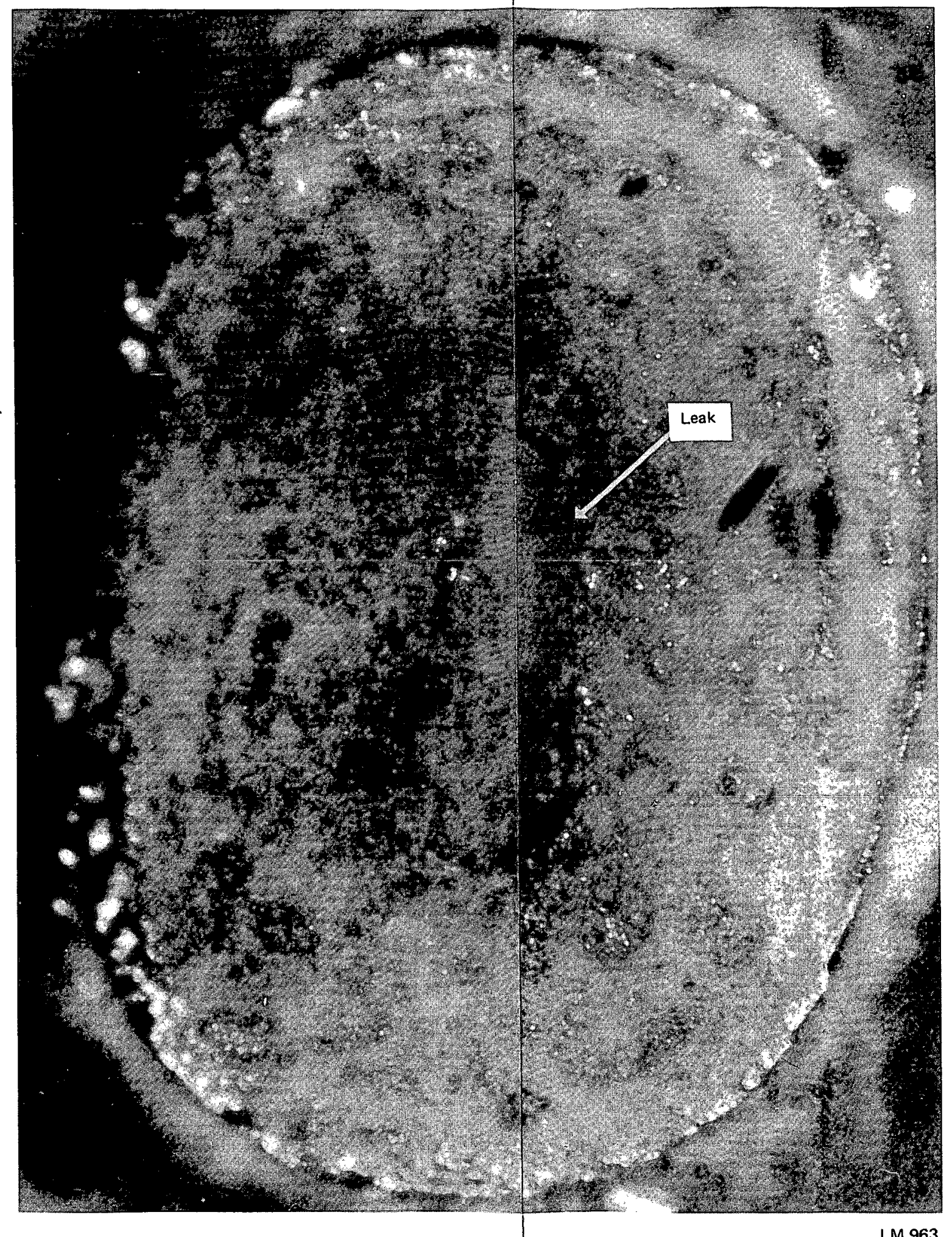

\begin{tabular}{l} 
Figure 9. OPTICAL MICROGRAPH OF $5 \times 10^{-5} \mathrm{~atm}-\mathrm{cm} 3 / \mathrm{s}$ LEAK A, PRIOR TO DYE-PENETRANT TEST. (150X) \\
\hline
\end{tabular}

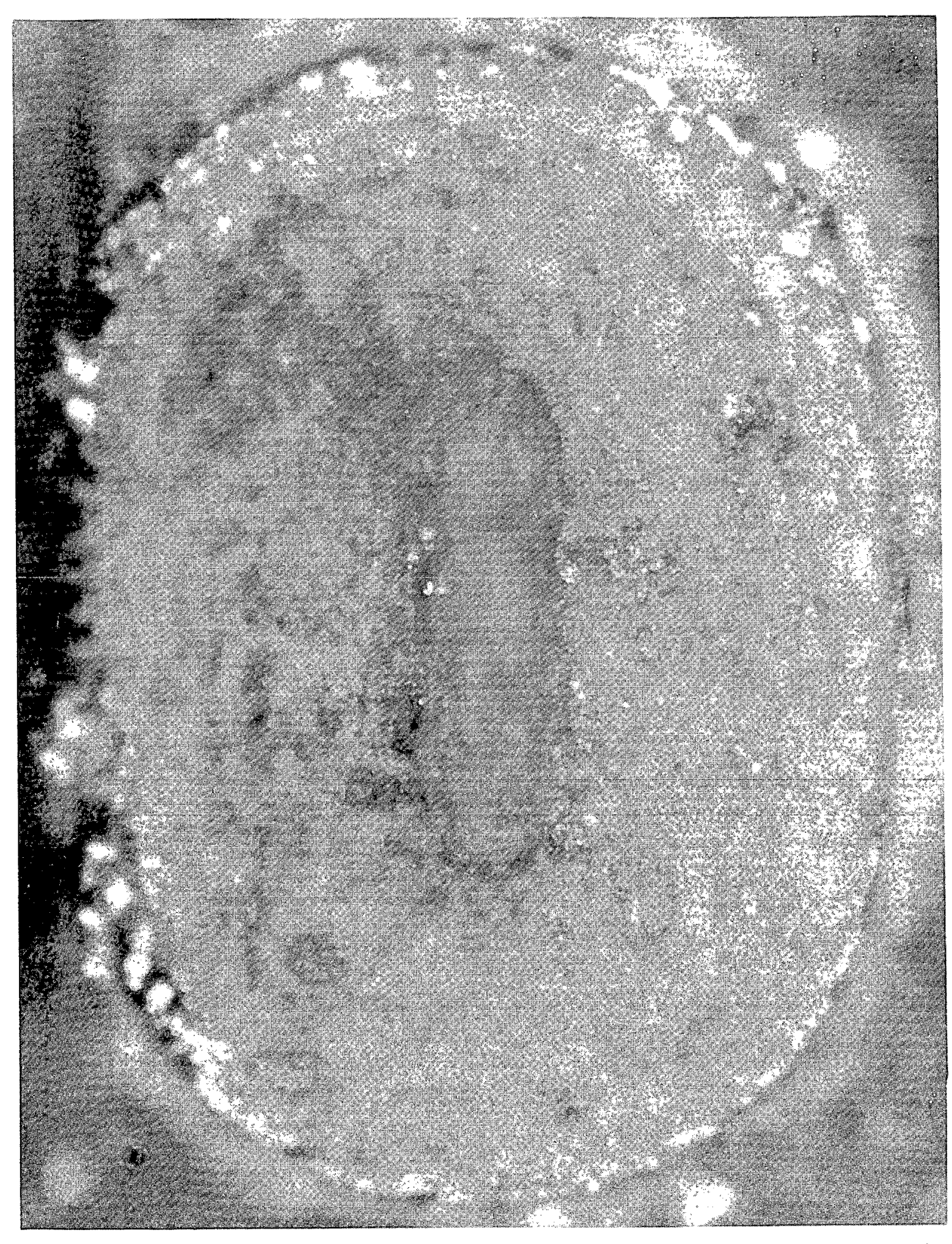

Figure 10. OPTICAL MICROGRAPH OF $5 \times 10^{-5} \mathrm{~atm}^{-\mathrm{cm}^{3} / \mathrm{s} \text { LEAK A, AFTER DYE-PENETRANT TEST. (150X) }}$ 


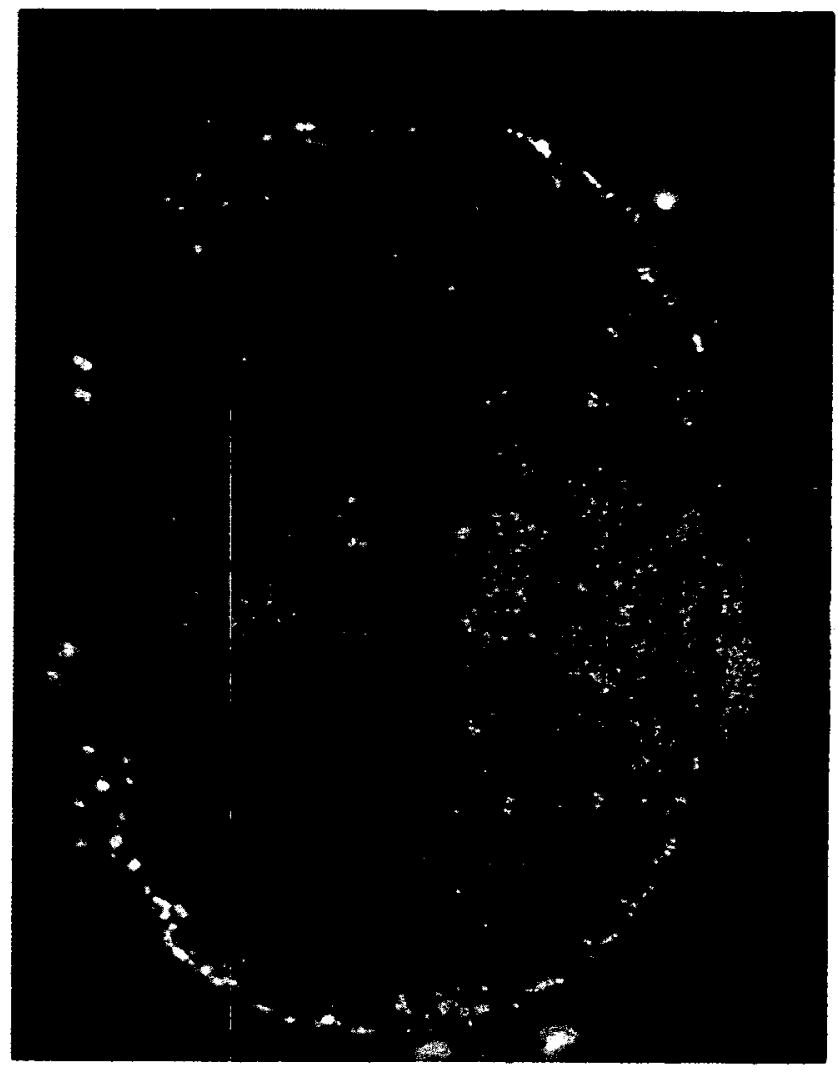

LM 967

Figure 11. OPTICAL MICROGRAPH OF $5 \times 10^{-5} \mathrm{~atm}-\mathrm{cm}^{3} / \mathrm{s}$ LEAK A, AFTER DYE.PENETRANT TEST. (Note retention of red dye; 75X.)

Table 2

LEAK RATES OF CRIMPED TUBE LEAKS SUBJECTED TO DYE-PENETRANT TESTING

\begin{tabular}{|c|c|c|c|c|}
\hline \multirow[b]{2}{*}{$\begin{array}{c}\text { Tube } \\
\text { Identification }\end{array}$} & \multicolumn{4}{|c|}{$\begin{array}{c}\text { Leak Rate } \\
\text { (atm- } \mathrm{cm}^{3} / \mathrm{s} \text { helium) }\end{array}$} \\
\hline & $\begin{array}{c}\text { Before } \\
\text { Dye Check }\end{array}$ & $\begin{array}{l}1 \text { Hour After } \\
\text { Dye Check }\end{array}$ & $\begin{array}{l}\text { Change in } \\
\text { Leak Rate }\end{array}$ & $\begin{array}{l}1 \text { Week Atter } \\
\text { Dye Check }\end{array}$ \\
\hline A & $5 \times 10^{-5}$ & $3 \times 10^{-5}$ & $2 \times 10^{-5}$ & $2 \times 10^{-8}$ \\
\hline B & $6 \times 10^{-5}$ & $6 \times 10^{-5}$ & 0 & $4 \times 10^{-5}$ \\
\hline c & $6 \times 10^{-5}$ & $3 \times 10^{-6}$ & $5.7 \times 10^{-5}$ & $3 \times 10^{-5}$ \\
\hline D & $2 \times 10^{-4}$ & $2 \times 10^{-4}$ & 0 & $2 \times 10^{-4}$ \\
\hline$E$ & $1 \times 10^{-4}$ & $8 \times 10^{-5}$ & $2 \times 10^{-5}$ & $<1 \times 10^{-10}$ \\
\hline$F$ & $1 \times 10^{-6}$ & $<1 \times 10^{-8}$ & $1 \times 10^{-6}$ & $<1 \times 10^{-10}$ \\
\hline G & $2 \times 10^{-3}$ & $2 \times 10^{-3}$ & 0 & $2 \times 10^{-3}$ \\
\hline
\end{tabular}




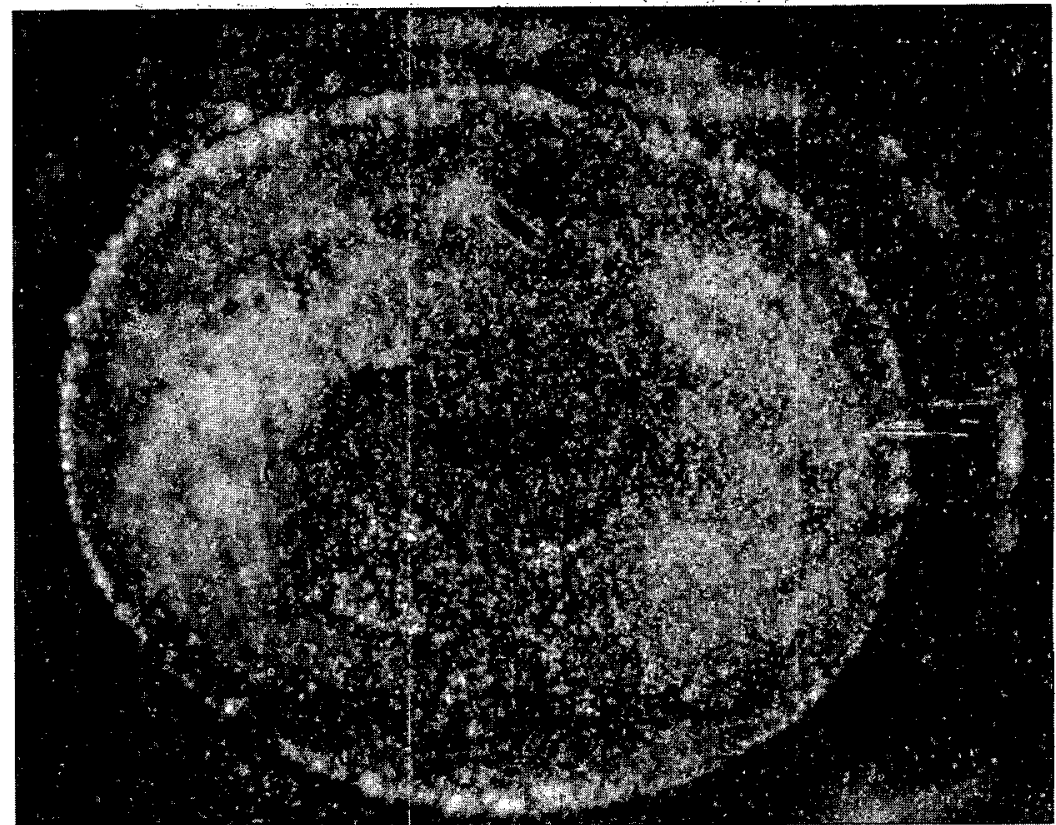

LM 964

Figure 12. OPT CAL MICROGRAPH OF $1 \times 10^{-4} \mathrm{~atm}-\mathrm{cm}^{3} / \mathrm{s}$ LEAK E. (Post dye test; $75 X .1$

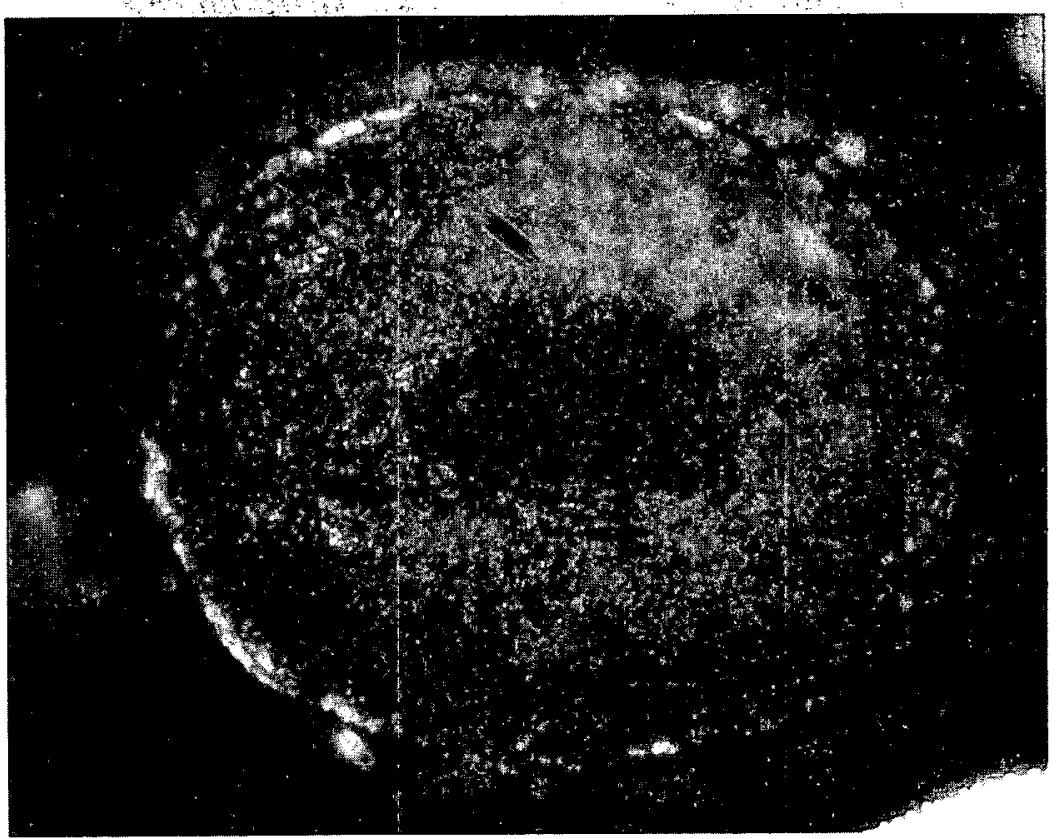

LM 965

Figure 13. OPTICAL MICROGRAPH OF $6 \times 10^{-5} \mathrm{~atm}-\mathrm{cm}^{3} / \mathrm{s}$ LEAK B. (Post dye test; $75 \mathrm{X}$.)

In order to prove the retention of the developer in and around the leak, two of the leaks were replicated using an extraction replica technique. (An extraction replica is one where the replicating medium pulls out particulate material from a surface when the replicating 


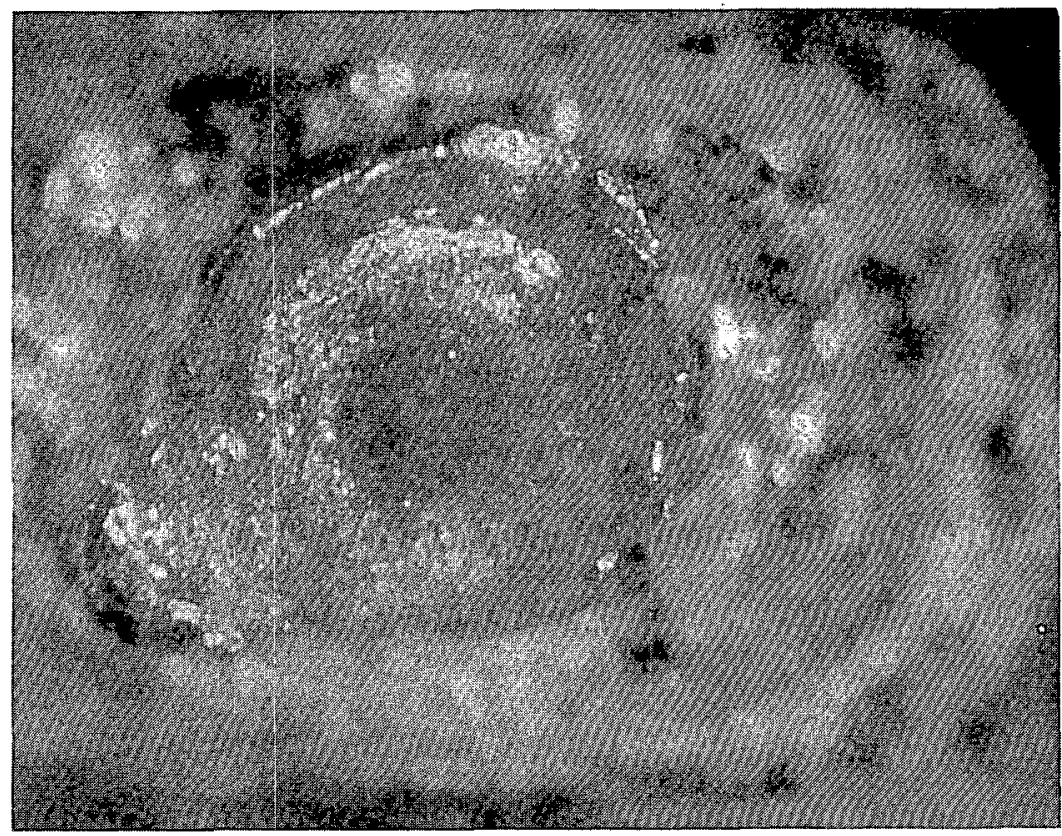

LM 966

Figure 14. OPTICAL MICROGRAPH OF $2 \times 10^{-4} \mathrm{~atm}-\mathrm{cm}^{3} / \mathrm{s}$ LEAK D. (Post dye test; $75 X$.

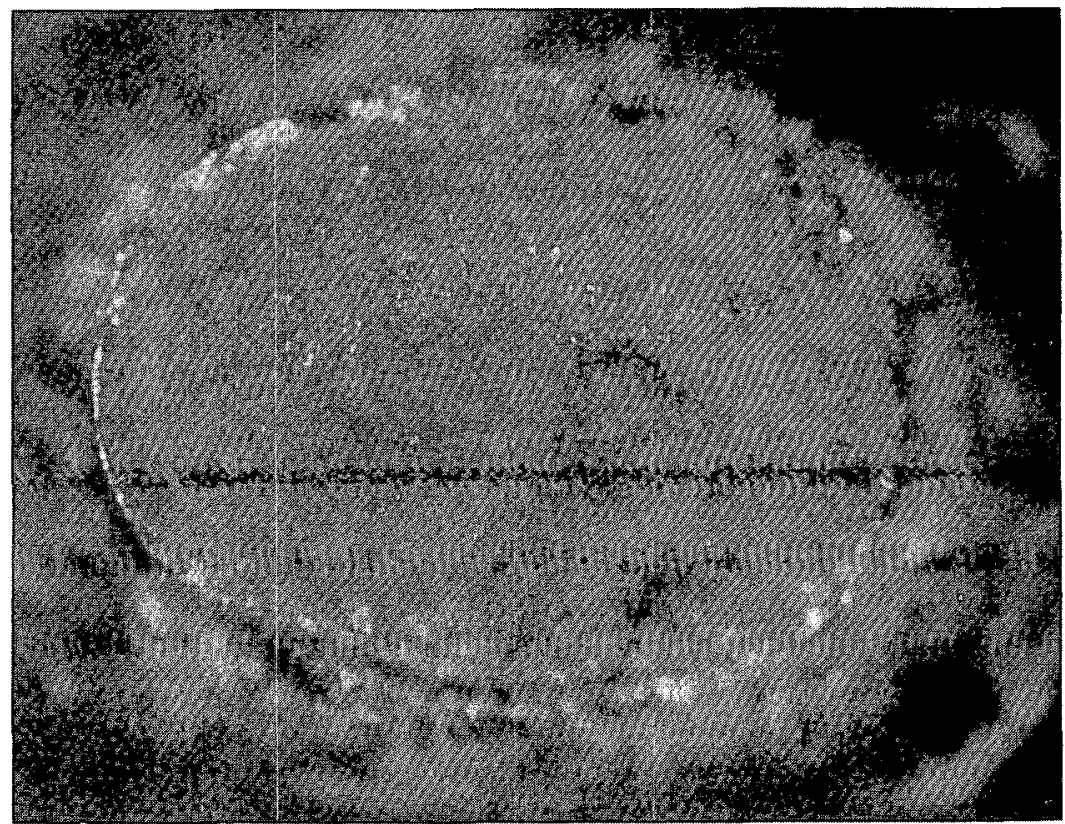

LM 968

Figure 15. OPTICAL MICROGRAPH OF $6 \times 10^{-5} \mathrm{~atm}-\mathrm{cm}^{3} / \mathrm{s}$ LEAK C. (Post dye test; 75X.)

medium is pulled from the surface.) The replicating medium used was a water solution of polyvinyl alcohol (PVA). After the replicas were removed, carbon was evaporated onto the PVA; the PVA was dissolved in water; and the replicas were examined in the transmission 
electron microscope. Figure 16 is a typical electron micrograph of the replicas. The particulate material observed is typical of the morphology of the particulates found in the developers used in the dye-penetrant procedure. (Compare Figure 16 with Figures 1 and 5 of this report.)

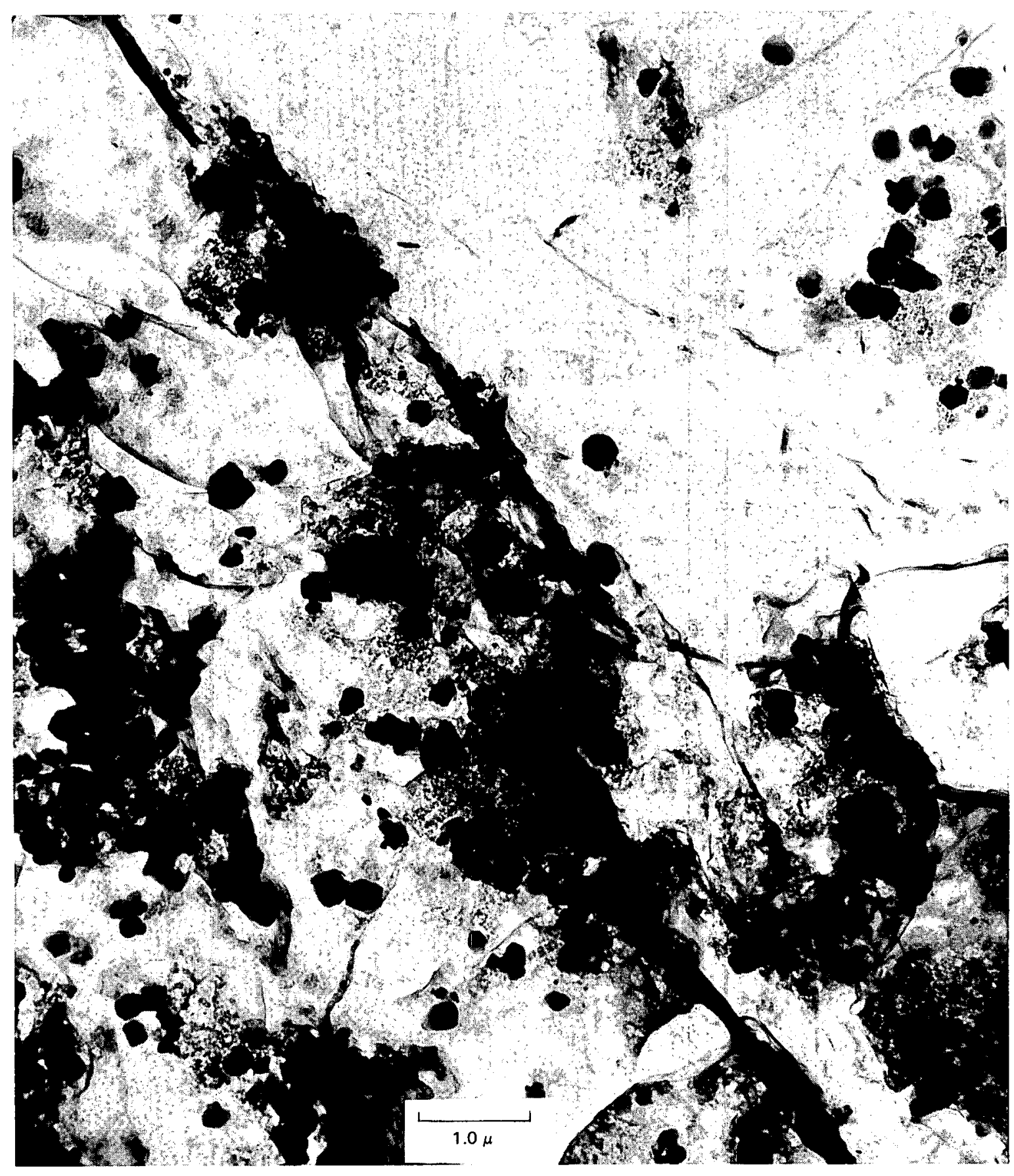

Figure 16. EXTRACTION REPLICA PULLED FROM DYE-TESTED LEAK. (17,250X) 


\section{CONCLUSIONS}

The results of this investigation have led to the following conclusions:

1. There are no particulate materials in the cleaner, Spotcheck SKC-S; penetrant, ZL-30A; emulsifier, ZE-3; or color-contrast penetrant, SKL-S.

2. Due to their low vapor pressures at room temperatures, the emulsifier, green dye ( $Z$ L-30A), and the color-contrast penetrant (red dye) can cause plugging of leaks by themselves.

3. Both the Zyglo ZP-9 and the Spotcheck SKD-S developers contain a large number of particulates. These particulates (identified as a mixture of $\mathrm{TiO}_{2}$ and $\mathrm{CaCO}_{3}$ ) fall into two size ranges: (1) Large particles-0.3 to $1.5 \mu \mathrm{m}$ in diameter, and (2) Small particles-0.02 to $0.06 \mu \mathrm{m}$ in diameter.

4. The particle size distribution of the particles found in the developers is the right size range to plug leaks of the $1 \times 10^{-5}$ and $1 \times 10^{-6}$ atm- $\mathrm{cm}^{3} / \mathrm{s}$ helium size.

5. The dyes and associated liquids plug leaks or reduce their value below detectable limits.

6. The standard cleaning described in the procedures after the dye-penetrant testing do not always remove all of the particulates in the developer.

7. Leaks that are $<1 \times 10^{-4}$ atm- $\mathrm{cm}^{3} / \mathrm{s}$ helium in magnitude are susceptible to plugging during dye-penetrant testing.

It is the conclusion of this study that the reliability of helium-leak-rate certification, after dye-penetrant testing, is significantly reduced. 


\section{REFERENCES}

1. R. D. Seals, H. L. Richards, S. S. Cristy, and O. P. Killeen, Surface Analysis of Residual Contaminants from Dye-Penetrant Testing, Union Carbide Corporation, Nuclear Division, Oak Ridge Y-12 Plant, Oak Ridge, Tenn., Y-2164 (1979).

2. J. A. Basford to R. S. Leete, Jr., Union Carbide Corporation, Nuclear Division, Oak Ridge Y-12 Plant, Oak Ridge, Tenn., Private Communication (Leak-Rate Calculations) (December 19, 1979). 


\section{Distribution}

Bendix - Kansas City

Carson, J. S.

Collins, M. C.

Deterding, W. H.

Hax, D. H.

Kessler, R. E.

MacCurdy, G. L.

Department of Energy - Albuquerque

Meyer, H. N., Jr. Whiteman, A. E.

Department of Energy - Oak Ridge

Hickman, H. D.

Poteat, R. M.

Department of Energy - Washington

Hoover, W. W.

\section{General Electric-Pinellas}

Brown, W. C.

Lawrence Livermore National Laboratory

Arnold, W. F.

Bender, C. F./Hanafee, J. E./Humphrey, J. R.

Carr, R. B. Wraith, C. L.

Colmenares, C. A.

Craig, R. J./Galles, H. L.

Frazer, J.W.

Gatrousis, C.

Inouye, W. S.

Landon, P. R.

Ludwig, E. R./Stisser, E. A.

MacMillan, K./Baxter, G. R.

Moon, D. W.

Rizzo, H. F.

Root, G. S./Sanford, C. B.

Staehle, G. G.Mondolowski, F. R.

Stock, R. P./Leider, H. R.

Stripeika, A. J.

Technical Information Division

Woodruff, R. D./Davis, D. L.

Los Alamos National Laboratory

Aragon, J.

Baker, F. B.

Baker, R. D.

Deinken, H. P./Kirby, R. S.

Eyster, E. H.Wechsler, J. J.
Hockett, J. E. Janney, D. H.

Larson, T. E./Taylor, G. W.

Library Services

McMillman, D. P.

Plassmann, E. H./Mosley, J. R.

Sheinberg, $H$.

VanBuren, D. T.

Waterbury, G. R.

Mason \& Hanger-Silas Mason Company-Pantex

Alley, C. D.

Cassidy, J. P.

Monsanto-Mound Facility

Hastings, J. D.

Records Management

Woltermann, H. A.

Oak Ridge Gaseous Diffusion Plant

Armstrong, R. C.

Levin, R. W.

Stief, S. S.

Wilcox, W. J., Jr.

Oak Ridge National Laboratory

Hopkins, C. C.

Ramsey, M. E.

\section{Oak Ridge $Y-12$ Plant}

Barkman, J. R.

Bernander, N. K.

Bieber, C. R.

Bostock, D. J./Butturini, W. G.

Briscoe, O.W.

Bright, G. R.

Bryant, D. P.

Burditt, R. B.

Cagle, G.W.

Cole, S. H.

Creech, E. T.

DeMarrota, L. J., Jr.

Dillon, J. J.

Dodson, W. H./Googin, J. M.

Dorsey, J. G.

Dritt, W. S.

Eager, M. H. (5)

Evans, G. W. 
Fee, G. G.

Ferguson, J. E. Haeusler, K. R. Harding, J. E. Hicks, W. R. Jackson, V. C. Jessen, N. C., Jr. Jones, F. W.

Kahl, K. G.

Keith, A.

Kite, H. T.

Koger, J. W.

Leete, R. S., Jr.

Long, P. J.

Mason, D. W.

McLaughlin, J. F. (5)

Mills, J. M., Jr.

Nicely, J. W.

Noey, J. L.

Preuss, H. M.

Robinette, B. K.

Schneider, P. G. (5)

Smith, R. D.

Tewes, W. E.

Thompson, W. H., Jr.

Williams, R. D.

Y-12 Central Files (master copy)

$Y-12$ Central Files (route copy)

$Y-12$ Central Files $(Y-12 R C)$

$Y-12$ Central Files (5)

Paducah Gaseous Diffusion Plant

Bewley, H. D.
Rockwell International - Rocky Flats

Carpenter, R. L.

Chanda, R. N.

Floyd, D. R.

Jiannetti, E./Skulski, R. W.

Liby, A. L.

Weidner, C. W.

Wiederecht, D. A.

Sandia National Laboratories - Albuquerque

Arthur, B. E.

Burchett, O.J.

Carli, G.

Heilman, L. J.

Hill, L. R.

Hillman, J. T./Jones, D. W.

Hollingsworth, $L$.

Saxton, H.J.

Spencer, W. J.

Whan, R. E.

Sandia National Laboratories - Livermore

Cozine, R. D.

Jones, M. O.

Mote, M. W.

Schuster, D. M.

Sheppard, H. R.

Technical Library

West, L. A.

Willis, A. R.

Savannah River Laboratory

Turno, D. H.

In addition, this report is distributed in accordance with the Category UC-38, Engineering and Equipment, as given in the Standard Distribution for Unclassified Scientific and Technical Reports, DOE/TIC-4500. 